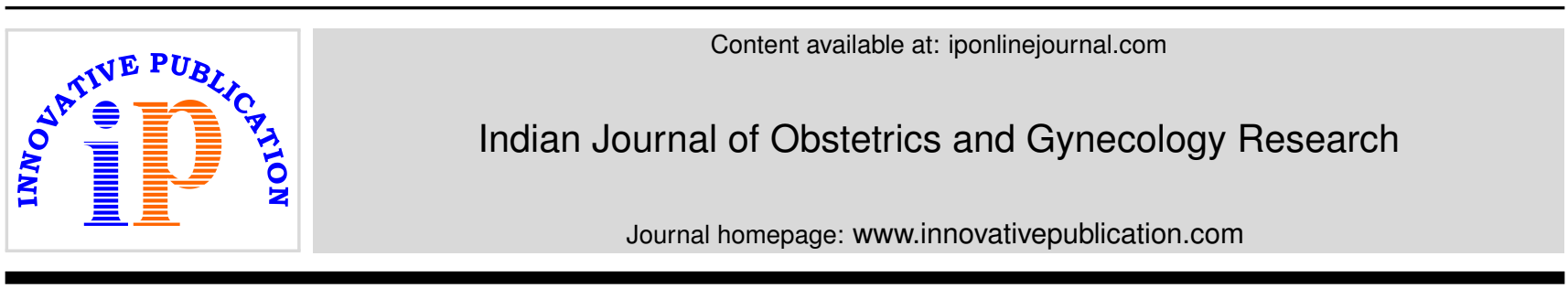

Original Research Article

\title{
Knowledge and attitude of infertile couples attending rural tertiary care centre
}

\author{
Gomathy $\mathbf{E}^{1}{ }^{1 *}$, Kondareddy Radhika ${ }^{1}$, Suman Shivanagoud Patil ${ }^{1}$, Ruth Sneha ${ }^{1}$ \\ ${ }^{1}$ Dept. of Obstetrics and Gynaecology, Sri Devaraj Urs Medical College, Kolar, Karnataka, India
}

\section{A R T I C L E I N F O}

Article history:

Received 27-08-2019

Accepted 04-11-2019

Available online 15-06-2020

\section{Keywords:}

Infertility

Knowledge

Attitude

Misconceptions

\begin{abstract}
A B S T R A C T
Introduction: Infertility defines as the inability to conceive naturally after one year of regular unprotected sexual intercourse. The chance to conceive depends on the length of sexual exposure, frequency of coitus and couples age. Only 5\% of the couples will conceive after one and half year or two years. Both males and females are equally responsible for the causes. Factors contributing to infertility have included male factors (sperm abnormality), female factors (an ovulation), couple factors (luteal phase defect, poor sperm production) and factors of unknown origin. Infertility has always existed but is now recognized as a global reproductive health problem and as an important component of reproductive health. It is a world wide health concern and affects $8-15 \%$ of couples. The knowledge regarding fertility and biology of reproduction was poor. Many women have little awareness about the fertility period and the risk factors.

Aim and Objectives: 1 . To assess the knowledge and attitude of infertile couples attending gynecological OPD. 2. To assess the possible risk factors and social consequences towards infertility.

Materials and Methods: This is a cross sectional observational study conducted on infertility patients attending to R 1 Jalappa hospital and research centre from February 2018 to July 2018.we designed a fertility questionnaire for both the partners with questions covering knowledge and attitude towards infertility.

Results: Out of 154 couples, prevalence of primary and secondary infertility was $72.1 \%$ and $27.9 \%$ respectively. The mean duration of infertility was 2.97 years. On scoring their level of knowledge, $(\mathrm{n}=$ $80)$ had inadequate, $(n=68)$ had moderate knowledge and $(n=6)$ had adequate knowledge. There was no statistically significant difference in the knowledge in relation to their educational qualification and type of infertility among participants.
\end{abstract}

(C) 2020 Published by Innovative Publication. This is an open access article under the CC BY-NC license (https://creativecommons.org/licenses/by-nc/4.0/)

\section{Introduction}

It is a dream of every married couple to have a child, which will bring happiness and joy into their life. Infertility is a disease of reproductive system, which affects men and women with almost equal frequency. ${ }^{1}$ The WHO defines primary infertility as inefficiency to conceive after a year of unprotected sex and secondary if not conceived following previous pregnancy. Infertility is a worldwide problem affecting 8-12 percent couple (50-80 million) during their reproductive lives (WHO, 1991). ${ }^{2}$ Infertility has stigmatised women from time immemorial. Women who are deemed to be infertile are often excluded from religious

\footnotetext{
* Corresponding author.

E-mail address: egomathy72@yahoo.com (Gomathy E).
}

practices and face many such social difficulties. Further, male factor of infertility is a taboo subject and is less often discussed in the society. This constrains the relationship of the couples resulting in divorces. Even if the couple seek treatment, women are often blamed for childlessness and she alone is expected to undergo the diagnostic procedures to know the cause of infertility.

A global survey of almost 17,500 women (mostly of childbearing age) from 10 countries revealed that knowledge regarding infertility and biology of reproduction was poor. ${ }^{3}$ Many women have little awareness of the period of the month in which they are most fertile and when to seek treatment. The risk factors for infertility include obesity, advanced maternal age, menstrual irregularities, sexually transmitted infections, smoking, alcohol consumption and 
many others. ${ }^{4}$

Increasing the level of knowledge of these factors may help to decrease the incidence of infertility by allowing couples to avoid certain risk factors that might lead to it. This knowledge may also help wider society to understand and empathize with the infertile couple, which may lead to a decrease in the psychological burden to those affected. ${ }^{5}$ More ever, patient education has been found to be a key aspect of patient satisfaction with infertility care.

Researches exploring the knowledge, behaviors, perceptions and practices regarding infertility or certain treatment options have been carried out in developed countries but very limited data is available from the Indian population despite high prevalence of infertility.

This present study was conducted in our hospital to evaluate the knowledge of infertile couples attending to outpatient department(OPD) about the risk factors associated with infertility and to assess their attitude towards various methods of infertility treatment.

\section{Aim and Objectives}

1. To assess the knowledge and attitude of infertile couples attending gynecological OPD.

2. To assess the possible risk factors and social consequences towards infertility.

\section{Materials and Methods}

A prospective observational study was conducted on infertility patients attending to $\mathrm{R} 1$ Jalappa hospital and research centre from February 2018 to July 2018, on all the infertile couples $(n=154)$. Recruitment was based on the couple's willingness to answer the questionnaire. The couples were informed about the study and offered knowledge and attitude based questionnaires during clinical history taking. The questionnaire contains 16 knowledge based and 7 attitude based questions. Their level of knowledge was assessed by giving score 1 to correct answer, Zero for wrong and those do not know the answer. Those who scored $<50 \%$ were considered to have inadequate, those with scores $>50$ to $75 \%$ as moderately adequate and those with scores $>75 \%$ adequate knowledge regarding infertility.

\section{Results}

\subsection{Knowledge and misconceptions regarding related to infertility}

Table 2 shows the response of infertile towards risk factors associated with infertility. In our study, most of the patients $(>70 \%)$ of respondents were aware the common risk factors such as advanced age, obesity, irregular menstrual cycle, stress, advantages of regular exercise. But only 55\% respondents were aware about fertile period.
In our study only $50 \%$ were aware that smoking reduces the sperm parameters in men and $57 \%$ were aware that increased age in men also reduces fertility.

\subsection{Attitude towards infertility and its social consequences}

Table 3 shows the response of infertile patients to some attitudinal statements towards infertility and its social consequences. In our study, $70 \%$ of couples labelled infertility as disease. Only $15.5 \%$ were that it was a problem of the couple and needed investigation of the couple simultaneously. In our study, we found that $91.5 \%$ of females were blamed by the family members and the society inspite of the fact that the cause may be related to any one of the partner.

\section{Discussion}

In a survey among reproductive age women our data identified significant knowledge gaps and misconceptions surrounding the reproductive health and conceptions. Many women have limited understanding regarding risk factors related to conception and infertility.

The rate of infertility in India is $10-14 \%$. The mean age of our study was 26 years for female and 30 years for male. Only $10 \%$ were higher education status among females and $20 \%$ are graduates among males.

According to Bunting and Boivin et $\mathrm{al}^{6}{ }^{2007}$, knowledge about fertility issues is a core motivator for fertility problems. A Global survey revealed inadequate knowledge of women regarding infertility ${ }^{3}$ our study also demonstrated that the participants had inadequate knowledge about the risk factors associated with infertility.

In our study, $75 \%$ of female partners were aware that increasing age results in decline in fertility which is similar to study by Bunting and Boivin et $\mathrm{al},{ }^{6}$ but there was lack of awareness of the significance of age for declining fertility among childless Canadian women ${ }^{7}$ and Australian women, ${ }^{8}$ and among the University students in Sweden. ${ }^{9}$

In our study, we found that $77 \%$ were aware that obesity has negative effects on infertility which is similar to Abolfotouh et al., ${ }^{10}$ Brannian et al., ${ }^{11}$ Bunting et al. ${ }^{12}$ study and Daniluk et al. ${ }^{7}$ study.

In our study, we found that $81 \%$ women were aware that irregular cycles may be a cause for delay in pregnancy, but in Abolfotouh et al ${ }^{10}$ study only $64 \%$ were aware about it.

It is crucial to know about the fertile period for a women, when she should try to conceive. In our study, fertile period was known to only $55 \%$ participants similar to Ali et al ${ }^{13}$ $48 \%$ were aware of it.

In our study $82.5 \%$ of female partners were not aware about the genital tract infections as risk factor for infertility. Since, diagnosis and treatment of genital tract infections can prevent the major sequel, the tubal block, awareness of 
Table 1: Demographic data (Parameters)

\begin{tabular}{lll}
\hline Mean age of female (years) & $26.79 \pm 4.721$ & Range 20-45 years \\
Mean age of male (years) & $30.87 \pm 4.168$ & Range 25-48 years \\
Type of infertility & Primary $-111(72.1 \%)$ & Secondary $-43(27.9 \%)$ \\
Mean duration of infertility & Primary $-2.29 \pm 1.093$ & Secondary-4.73 \pm 1.78
\end{tabular}

Table 2: Response of couple about knowledge based questionnarie

\begin{tabular}{|c|c|c|c|}
\hline Questions & Yes & No & Don't Know \\
\hline $\begin{array}{l}\text { Do you think increasing age in women may delay to } \\
\text { achieve pregnancy? }\end{array}$ & $116(75.3 \%)$ & $26(16.9 \%)$ & $12(7.8 \%)$ \\
\hline Does obesity in a women delay the fertility? & $119(77.3 \%)$ & $16(10.4 \%)$ & $19(12.3 \%)$ \\
\hline $\begin{array}{l}\text { Do you think irregular cycle may be a cause for delay in } \\
\text { achieving pregnancy? }\end{array}$ & $124(80.5 \%)$ & $14(9.1 \%)$ & $16(10.4 \%)$ \\
\hline $\begin{array}{l}\text { Does pain in lower abdomen during periods and during } \\
\text { sexual intercourse delays in pregnancy? }\end{array}$ & $30(19.5 \%)$ & $53(34.4 \%)$ & $71(46.1 \%)$ \\
\hline $\begin{array}{l}\text { What do you mean by fertile period in a women having } \\
\text { regular cycle? }\end{array}$ & $84(54.54 \%)$ & $60(38.96 \%)$ & $10(6.5 \%)$ \\
\hline $\begin{array}{l}\text { Do you think foul smelling discharge per vagina in a } \\
\text { women is a cause for pregnancy delay? }\end{array}$ & $27(17.53 \%)$ & $40(25.97 \%)$ & $87(56.5 \%)$ \\
\hline Does OCP use in past delay conception in the women? & $74(48.06 \%)$ & $20(12.98 \%)$ & $60(38.96 \%)$ \\
\hline $\begin{array}{l}\text { Do you think frequency of intercourse increases the chance } \\
\text { of pregnancy? }\end{array}$ & $94(61 \%)$ & $38(24.7 \%)$ & $22(14.3 \%)$ \\
\hline $\begin{array}{l}\text { Does lying down in bed for long time after sexual } \\
\text { intercourse increase the pregnancy chance? }\end{array}$ & $108(70.1 \%)$ & $21(13.7 \%)$ & $25(16.2 \%)$ \\
\hline Do you think stressful life in a women affects her fertility? & $139(90.3 \%)$ & $07(4.5 \%)$ & $08(5.2 \%)$ \\
\hline Do you think delay in pregnancy runs in families? & $51(33.1 \%)$ & $57(37 \%)$ & $46(29.9 \%)$ \\
\hline $\begin{array}{l}\text { Do you think exposure to environmental pollutant reduce } \\
\text { fertility }\end{array}$ & $70(45.4 \%)$ & $32(20.8 \%)$ & $52(33.8 \%)$ \\
\hline $\begin{array}{l}\text { Do you think regular exercise by a women increases her } \\
\text { fertility? }\end{array}$ & $118(76.6 \%)$ & $14(9.1 \%)$ & $22(14.3 \%)$ \\
\hline Does smoking reduce sperm parameters in men? & $78(50.6 \%)$ & $44(28.6 \%)$ & $32(20.8 \%)$ \\
\hline Do you think increasing age in men reduces fertility? & $87(56.5 \%)$ & $40(25.97 \%)$ & $27(17.53 \%)$ \\
\hline $\begin{array}{l}\text { Do you think a women conceived previously might have } \\
\text { problems to conceive again? }\end{array}$ & $48(31.2 \%)$ & $81(52.6 \%)$ & $25(16.2 \%)$ \\
\hline
\end{tabular}

Table 3: Response of couple about attitude based questionnarie

\begin{tabular}{|c|c|c|c|}
\hline Questions & Yes & No & \\
\hline Do you think infertility is a disease? & $108(70.1 \%)$ & $46(29.9 \%)$ & \\
\hline Who do you think it should be investigated first? & $\mathrm{H}-5(3.24 \%)$ & $\mathrm{W}-125(81.16 \%)$ & B- $24(15.58 \%)$ \\
\hline Who is being blamed for infertility in the society? & $\mathrm{H}-1(0.7 \%)$ & $\mathrm{W}-141(91.5 \%)$ & $\mathrm{B}-12(7.8 \%)$ \\
\hline $\begin{array}{l}\text { Do you think it is socially acceptable to have a test } \\
\text { tube baby? }\end{array}$ & $8(5.19 \%)$ & $132(85.71 \%)$ & $14(9.1 \%)$ \\
\hline $\begin{array}{l}\text { If a couple cannot have a child, do you think they } \\
\text { should adopt? }\end{array}$ & $18(11.7 \%)$ & $128(83.11 \%)$ & $8(5.19 \%)$ \\
\hline $\begin{array}{l}\text { Do you think your husband should donate sperm } \\
\text { to help an infertile couple to have a baby? }\end{array}$ & $12(7.8 \%)$ & $108(70.12 \%)$ & $34(22.1 \%)$ \\
\hline $\begin{array}{l}\text { Are you interested to donate your egg to help an } \\
\text { infertile couple to have a baby? }\end{array}$ & $10(6.5 \%)$ & $106(68.8 \%)$ & $38(24.7 \%)$ \\
\hline
\end{tabular}

Table 4: Levels of knowledge

\begin{tabular}{lcc}
\hline Knowledge & No & Percentage $(\%)$ \\
Inadequate knowledge & 80 & 51.9 \\
Moderately adequate knowledge & 68 & 44.2 \\
Adequate knowledge & 8 & 3.9 \\
\hline
\end{tabular}


genital infection as a risk factor is highly required in our society.

In our study, $48 \%$ had misconception that use of oral contraceptive affect their fertility status and $38 \%$ were not aware about the OCP role, this misconception may have led to unwanted pregnancy loss, but in Ali et al. ${ }^{13}$ study, $61 \%$ correctly highlighted use of OCP affecting the fertility. Study conducted by Bunting ${ }^{5}$ also highlighted that participants had a false belief that use OCP as risk factor for infertility.

In our study, $70 \%$ of the respondents had the false belief that lying down in bed for long time after sexual intercourse increases the chances of pregnancy, which is similar to Bunting and Boivin et al. ${ }^{5}$ study in which participants believed in the myth that lying down for 10 minutes after sex increases the pregnancy rate.

In our study, $90 \%$ females were aware about the negative effect of stress on fertility, which is had similar to other studies.

In our study, only $33 \%$ of couple belief that infertility runs in family but no other study commented on hereditary nature of fertility.

In our study, $56.5 \%$ women thought that increasing man's age reduces the chance of infertility, which is similar to Daniluk and Koert et al. study. ${ }^{7}$

In our study, we found that $52 \%$ women had the misconception there will be no problem for further conception; due to this false belief there was delay in their consultation.

Considering attitude of people in our study, 70\% labelled infertility as disease, but in Ali et al. ${ }^{13}$ study, only $44 \%$ opined that infertility as disease.

Unnecessary blame on a woman for infertility can potentially effect her self-esteem and might socially cripple her. In our study, we found that $90 \%$ of women thought that they were blamed by the society for infertility and this is similar to Ali et al. ${ }^{13}$ and Sami et al. ${ }^{14}$ studies.

In our study, we found that $>80 \%$ patients were not aware about the mode of treatment available such as IVF and adoption. Since child adoption is an available option for infertile couples, many couples with incurable infertility in advanced countries are willing to adopt babies. In our rural set up only $11.5 \%$ couples agreed for adoption.

We also found that $70 \%$ of infertile couples husband's were not willing to help infertile couple by sperm donation and this is similar to Sohrabvand et al. ${ }^{15}$ study were $98.7 \%$ opposed sperm donation.

In our study response of infertile females towards egg donation was poor, but in a study conducted in Turkey by Isikoglu et al., ${ }^{16}$ the proportion of positive respondents towards oocyte donation was nearly $85 \%$.

\section{Limitations of study}

Most of the patients attending our OPD were referred or previous treatment failure cases.
Only a small group of population was studied.

\section{Conclusion}

Infertility is common problem affecting $10-15 \%$ of the population. The knowledge about infertility and its risk factors is generally limited among the participants, inspite of their educational status. In fact, there are a lot of misconceptions, such as OCPs can cause infertility. The cultural and religion perspective about ART is unclear, which has resulted in its reduced acceptability. There should be some recommendations for enhancing the reproductive healthcare and increase the knowledge regarding it. We should create effective strategies for improving the awareness and education regarding fertility by conducting counseling sessions, interactive classes and web based and media based education.

\section{Source of Funding}

None.

\section{Conflict of Interest}

None.

\section{References}

1. Callahan LT, Caughey AB. Infertility and assisted reproductive technologies. In: Blueprints Obstetrics and Gynecology. 5th Edition. Lippincott Williams \& Wilkins; 2008. p. 275-89.

2. World Health Organization. WHO/MCH/91.9. Geneva: World Health Organization; Infertility: Tabulation of Available Data on Prevalence of Primary and Secondary Infertility; 1991.

3. What you never know about fertility. World Fertility Awareness Month; 2006.

4. Namujju J. Knowledge, attitudes and practices towards infertility among adults 18-40years in Kalisizo, Rakai District in Uganda. Uganda Scholarly Digital Library. 2008;.

5. Bunting L, Boivin J. Knowledge about infertility risk factors, fertility myths and illusory benefits of healthy habits in young people. Hum Reprod. 2008;23(8):1858-64.

6. Buting L, Biovin J. Decision-making about seeking medical advice in an internet sample of women trying to get pregnant. Hum Reprod. 2007;22(6): 1662-8.

7. Daniluk JC, Koert E, Cheung A. Childless women's knowledge of fertility and assisted human reproduction: identifying the gaps. Fertil Steril. 2012;97(2):420-6.

8. Hammarberg K, Setter T, Norman RJ, Holden CA, Michelmore J, Johnson L. Knowledge about factors that influence fertility among Australians of reproductive age: a population-based survey. Fertil Steril. 2013;99(2):502-7.

9. Svanberg AS, Lampic C, Karlström PO, Tydén T. Attitudes toward parenthood and awareness of fertility among postgraduate students in Sweden. Gend Medi. 2006;3(3):187-95.

10. Abolfotouh M, Alabdrabalnabi AA, Albacker RB, Al-Jughaiman U, Hassan SN. Knowledge, attitude, and practices of infertility among Saudi couples. Int J Gen Med. 2013;6:563-73.

11. Brannian JD. Obesity and fertility. S D Med. 2011;64(7):251-4.

12. Bunting L, Tsibulsky I, Boivin J. Fertility knowledge and beliefs about fertility treatment: findings from the International Fertility Decisionmaking Study. Human Reprod. 2013;28(2):385-97. 
13. Ali S, Sophie R, Imam AM, Khan FI, Ali SF, Shaikh A, et al. Knowledge, perceptions and myths regarding infertility among selected adult population in Pakistan: a cross-sectional study. BMC Public Health. 2011;11(1):760.

14. Sami N, Ali TS. The cultural politics of gender for infertile women in Karachi. In: Pakistan: Proceedings of the FOTIM Gender Studies Conference, Pakistan; Pretoria, South Africa; 2006.

15. Schmidt L. Infertile couples assessment of infertility treatment. Acta Obstet Gynecol Scand. 1998;77(6):649-53.

16. Isikoglu M, Senol Y, Berkkanoglu M, Ozgur K, Donmez L, StonesAbbasi A. Public opinion regarding oocyte donation in Turkey: first data from a secular population among the Islamic world. Human Reprod. 2006;21(1):318-23.

\section{Author biography}

\section{Gomathy E Professor}

Kondareddy Radhika Senior Resident

Suman Shivanagoud Patil Senior Resident

Ruth Sneha Assistant Professor

Cite this article: Gomathy E, Radhika K, Patil SS, Sneha R.

Knowledge and attitude of infertile couples attending rural tertiary care centre. Indian J Obstet Gynecol Res 2020;7(2):177-181. 